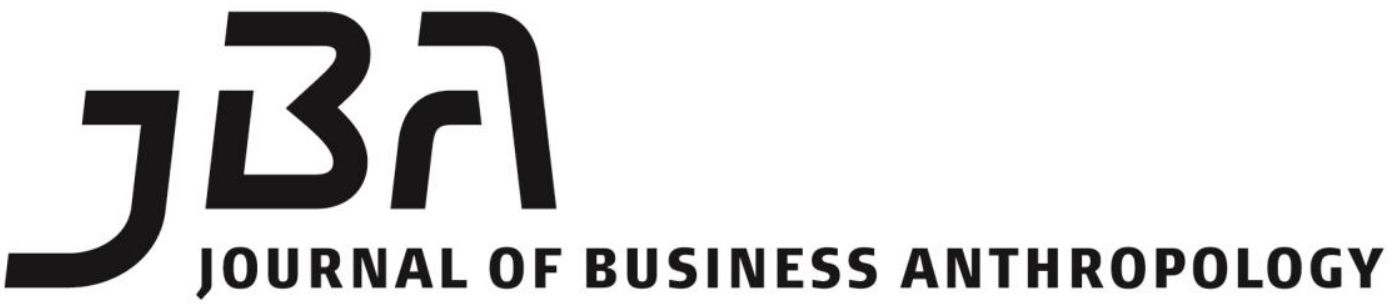

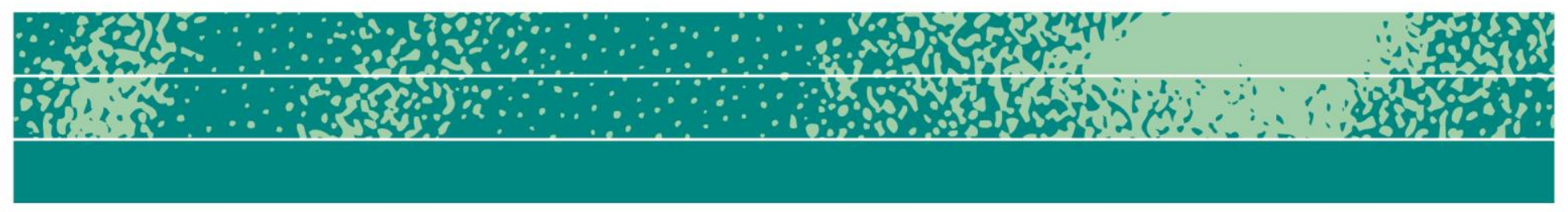

1984 Unpublished Article

\section{Why do the Indians Wear Adidas? Or, Culture Contact and the Relations of Consumption}

Richard R. Wilk and Eric J. Arnould

\begin{abstract}
The study of the consumption of goods has never achieved the prominence in anthropology of either production or exchange. Yet the accelerating consumption of western goods in non-western societies is one of the most obtrusive cultural and economic trends of the last three centuries. This article addresses the general issue of why goods flow between cultural groups by re-examining the concept of consumption. It raises questions of importance to studies of development, material culture, ethnohistory, and symbolic anthropology.
\end{abstract}

\section{Keywords}

Economic anthropology, consumption, acculturation, symbolic anthropology, material culture 


\section{Introduction}

Peruvian Indians carry around small rectangular rocks painted to look like transistor radios. ${ }^{1}$ San Blas Cuna households hoard boxes of dolls, safety pins, children's hats and shoes, marbles, enamelware kettles, and bedsheets with pillowcases in their original cellophane wrappings. Japanese newlyweds cut three-tiered white frosted inedible cakes topped with plastic figures in western dress. Q'eqchi' Maya swidden farmers relax at night listening to Freddie Fender on a portable cassette player while Bana tribesmen in Kako, Ethiopia, pay a hefty price to look through a Viewmaster at "Pluto Tries to Become a Circus Dog." Tibetans, bitterly opposed to Chinese rule, sport Mao caps. Young Wayana Indians in Surinam spend hours manipulating a Rubik's cube. The elaborate White Mountain Apache puberty ceremony features the massive redistribution of soda pop. When a Swazi Princess weds a Zulu King, she wears red touraco wing feathers around her forehead and a cape of windowbird feathers and oxtails. He wears a leopard skin cloak, and both are recorded with a Kodak movie camera while the band plays "The Sound of Music." In Niger, pastoral Bororo nomads race to market on camelback, carrying beach umbrellas. Veiled noble Tuareg men carry swords modeled after the Crusaders" weapons and sport mirrored sunglasses with tiny hearts etched into the lenses.

Behind these incongruous and sometimes humorous images lies a serious anthropological problem which has never achieved the prominence it deserves. In their concern with production and exchange, anthropologists have tended to slight the importance of consumption. Yet through the more poignant examples of the introduction of iron axes to stone-age Australians and powdered milk to numerous third-world mothers, we are all familiar with the central role of consumption patterns in the process of culture change. Because we come from a society in which consumerism and conspicuous consumption are accepted as part of human nature, we see this process as being somehow obvious and selfexplanatory. So, on the contrary, we suggest that this is a complex, problematic topic which needs to be integrated with contemporary studies of development, material culture, and symbolism. We are actually asking a number of different questions about the reasons for the transfer of objects between cultures, and we intend to distinguish a number of underlying causes and motives beneath what seems, at first, to be a unitary phenomenon.

\footnotetext{
1 Acknowledgements: Many people have had their hands, directly and indirectly in helping us write this paper. Susan Greenhalgh, Robert Netting and Richard Randolph have read drafts and offered comments. William Rathje, Michael Schiffer and Michael Reilly gave us ideas that were very influential. Harold Wilhite and Barbra Heyerdahl provided a kitchen for us to work in. None has any responsibility for the final project's errors.
} 
We will pose some key questions to help divide up and define the realm of inquiry. First, why are some cultures more resistant or more accepting of objects from outside their own symbolic and economic system? Second, given the range of possible objects or artifacts which could be adopted or incorporated, why and how are some selected and others rejected? Third, why are the consequences of adoption in different circumstances destructive, constructive, or benign? Fourth, and perhaps most generally, what are the motives which impel people, in so many diverse settings, to seek and adopt novel artifacts, customs, and symbols?

To answer these questions, we think it necessary to introduce the concept of "mode of consumption" to describe the ways in which objects are used materially and symbolically within a society. While our ultimate goal is a classificatory scheme for consumption, we intend this to be a complement to existing schemes for classifying economic systems in terms of exchange and modes of production. This will allow us to define the ways in which consumption articulates in different ways with exchange and production.

In this essay we will limit our discussion to a number of examples, and will concentrate on the symbolic dimension of artifacts and objects rather than on their utilitarian aspects (which have been treated thoroughly elsewhere, notably by historical archaeologists). We begin with a quick survey of relevant literature in a number of fields, and then present an analytical scheme for understanding different modes of consumption. We then suggest some general, testable answers to the questions we have posed above, and define the topical areas which are most in need of further inquiry.

\section{Themes in the literature}

Speaking on the question of how and why consumers make choices in the global marketplace, Paul Baran (1962: xii-xiv) defines two ideological positions which are worth quoting at some length:

The conservative reaction ... appears in two variants. One school of thought deals with the problem by denying its existence. This school holds that the molding of consumers" tastes and preferences by the advertising and high-pressure sales efforts of corporate business is nothing but a bogey, because in the long run no amount of persuasion and no ingenuity of salesmanship can change "human nature," can force upon the consumer what he does not want... Another conservative current of thought... freely acknowledges that the consumer's revealed preferences have nothing in common with the traditional notion of consumer choice, that the power of the giant corporations is such as to mold consumers" tastes and preferences for the benefit of 
corporate interests, and that all of this has a deleterious effect on both our economy and our society... This is not the stance of the so-called liberal. Considering the consumers" revealed preferences to be the source of our societies irrational allocation of resources... the liberal is exercised about the pernicious impact of advertising, about fraudulent product differentiation and artificial product obsolescence; he inveighs against the quality of culture purveyed by the educational system, Hollywood, the newspapers, the radio and TV networks...

Baran defines three of the existing explanations for acculturation and the diffusion of consumer goods. We find other root causes proposed or elaborated upon elsewhere:

1. Human desires are insatiable... This gives rise to constant discontent in the human mind and a weariness of the things they possess; and it is this which makes them decry the present, praise the past, and desire the future (Machiavelli, as quoted in Burnham 1968);

2. In most nations, foreign trade has preceded any refinement of home manufactures and given birth to domestic luxury. The temptation is stronger to make use of foreign commodities which are ready for use and which are entirely new to us, than to make improvements on any domestic commodity, which always advance by slow degrees, and never affect us by their novelty (Hume 1752, cited in Wilks 1979: 7);

3. The bourgeoisie, by the rapid improvement of all instruments of production, by the immensely facilitated means of communication, draws all, even the most barbarian nations into civilization. The cheap prices of its commodities are the heavy artillery with which it batters down all Chinese walls, with which it forces the "barbarians" intensely obdurate hatred of foreigners to capitulate (Marx and Engels 1848: 53);

4. As native subsistence systems undergo pressure because of sedentation and encroachment, people respond by intensifying subsistence production and adopting different technologies in order to do so....The availability of steel axes, knives and machetes, and firearms is especially important. These are more efficient and durable than their handmade counterparts... "Luxury" items... may be a way of conserving capital because such items as radios, wristwatches, and handguns hold their value batter than cash...Thus, we think that while industrial goods may have an intrinsic allure to native peoples, practical requirements brought about by sedentation, encroachment, colonization, and subsistence intensification are of greater importance (Gross et al. 1979: 1048-1049). 
We abstract the following contradictory themes from these representatives of a much more extensive literature:

- Consumers are essentially autonomous and uninfluenced by advertising or other pressure. Demand for goods flows in some unspecified fashion from human nature, which is inherently acquisitive (see sociobiologists such as Wilson 1975);

- Demand for goods is essentially the product of corporate and business leadership and coercion through advertising or force. Some see this as benign or progressive, while others see it as pernicious, and seek to regulate or modify this power for more rational purposes;

- Novelty, as represented by "foreign" goods, is inherently interesting to human beings, so that artifacts from other systems will always be more attractive than equivalent local products;

- That ideological and material domination causes the flow of goods from capitalist to precapitalist cultures, as part of the extraction of surplus value in the process of "primitive accumulation";

- Some goods, mostly those manufactured in industrial societies, are technologically superior to native products. The adoption of new products is part of an adaptive strategy for coping with pressure on subsistence production;

- That, as Freud proposed, "acquisitiveness and possessiveness come from fixations at or regressions to two different stages of psychological development" (Belk 1982:19). These are oral fixations or anal fixations, stemming from incidents in psychological ontogeny. This last factor will not be dealt with as a central issue in this essay, although psychological explanation is a major orientation in studies of consumer behavior.

These various themes are used and interwoven in a number of implicit and explicit ways in a number of bodies of literature. Next we will briefly examine various schools of thought in different disciplines, and bring in some concepts from economic and symbolic anthropology which can help resolve issues of causality.

Within anthropology, especially during the 1940s and 1950s, the issues of culture contact between "primitive" and industrialized society were treated within the category of "acculturation." A whole series of studies considered the impacts of technological change, culture contact, and economic development on non-western peoples (e.g. Mead 1955, Spicer 1952), often explicitly considering situations of forced change in which dominant political and economic systems disrupted "traditional" patterns. As long as the issue was enforced change, the question of motive on the part of traditional societies could be evaded. 
Nevertheless, case studies like that by Murphy and Steward (1956), proposed a model by which traditional peoples were "seduced" into dependence on imported manufactures and foodstuffs, through a process of luxuries becoming necessities. Foods, tools and ornaments, which at first were cheap, effective, or novel, drew people into market relations, which gradually expanded to include the majority of their material culture and livelihood. The cause of the process was the desire of western traders for the products-like fur and rubber-of native areas, and the progression of dependence was designed to intensify that production. In this model, indigenous peoples were essentially passively exploited through their initially innocent acquisitiveness.

Another theme in acculturation studies is that of emulation. In discussing the gradual intrusion of western material culture into San Blas Cuna life in the absence of any coercion or force, Stout (1947) claimed that a major motivation was the Cuna desire to mimic the dress and behavior of the foreign groups which they most admired. He pointed out that the Cuna borrowed heavily from the English and Americans who they admired (and received political support from), and virtually ignored the material culture of the Spanish and Panamanians with whom they were in conflict. This "desire, largely unconscious, to identify themselves through imitation and emulation with English-speaking whites" was seen as the outcome of "free selections" (Stout 1947: 108-109).

The unstated general principle, drawing on the prevailing diffusion theories, was that material culture "traits" are inherently mobile. Small, relatively unorganized societies are predominantly recipients, while larger and more dynamic societies are donors.

At the same time, this trend of "deculturation" was seen as an inevitable part of the process of increasing world trade and the growth of an amorphous "world culture." Material culture intrusion was merely a symptom of the progressive loss of the "little tradition" at the hands of the "great tradition." At the village scale, the process was motivated by the "increasing volume of trade and growing desire for cash wealth," which resulted in "a growing loss of interest, especially among the young men, in their own culture" (ibid., p. 77). "There is also a growing conflict between the old hospitality and sharing pattern and the new competitive and individualistic values" (ibid.).

While studies of acculturation were quite correct in linking flows of material culture to larger and more encompassing patterns of socioeconomic change, they used an inadequate macro-scale model of global historical economic processes. In addition, they never seriously questioned either "native" motivations for borrowing, or general assumptions about human economic rationality-a line of question which eventually led into the cul-de-sac of the formalist-substantivist debate (Godelier 1977). 
The recent flourishing of the "world systems" approach to economic history has similarly skirted important issues of consumption and demand. Wallerstein, in discussing early mercantile exploitation of the periphery, exclusively dwells on the demand for luxury goods in the core economies (1976). Demand for goods among the emerging elites of the periphery is again traced to the emulation of the elites in advanced countries (Furtado 1963). By concentrating on the flow of wealth from periphery to core, world systems theorists end up depending on Marx's explanation for flows in the opposite direction, that both are enforced through tribute, taxation, or ideological imperialism. Perhaps the most productive arguments about consumption patterns and the growth of demand to grow out of the study of world systems are those which focus on the growth of internal demand for imported goods within the core zone. The questions here are essentially the same ones we ask in this paper: 'Precisely how demand 'arises'; precisely how supply 'stimulates' demand even while filling it-and yielding a profit besides; precisely how 'demand' is transformed into the ritual of daily necessity and even into images of daily decency..." (Mintz 1979: 65).

Again the answers seem to lie, at least partially, in the supplanting of subsistence economies and self-sufficient economic enclaves by proletarianization and wage labor, and the concomitant dependence on purchased, imported goods. But as Wolf (1982) points out, this is not a uniform or unitary historical process. Furthermore, if the origins of proletarianization and wage labor are to be found partially in people's desires for the luxury products of the marketplace (as proposed by Murphy and Steward among many others), we are led into an explanatory paradox. If demand stimulates new relations of production, and production stimulates demand, it seems essential to settle the issue of the origin of demand.

Contemporary Marxist approaches to the spread of capitalist relations of production take a similar stance, oriented towards production and exchange rather than demand and consumption. The growth of consumerism is an inevitable by-product of the proletarianization of the workforce. "Commodity fetishism" grows as people compensate for their lack of control over production and exchange through an elaboration of their control over consumption (e.g. the poor rural Americans studied by Fitchen 1981). This seems a useful explanation for the maintenance of high-consumption rates among industrialized populations, but it sheds little light on the origin of those patterns and the particular choices of consumer goods in each case.

An influential, and often credible, argument about the growth of consumer demand in the modern "periphery" can be found in the laudatory and critical literature on multinational corporations (the modern practitioners of the "world systems approach"). Multinationals do an increasing business in luxury goods in both urban and rural areas of 
the underdeveloped world, and both proponents and critics agree that advertising campaigns, bolstered with more subtle ideological imperialism, are the effective agents. These billboards, prepared with the latest techniques of modern advertising, offer Technicolor fantasies of luxury, love, and power that no message from the Department of Health, however uplifting, is likely to disturb.

Throughout the underdeveloped world global corporations are thus successfully marketing the same dreams they have been selling in the industrialized world. Stimulating consumption in low-income countries and accommodating local tastes to globally distributed products is crucial to the development of an everexpanding Global Shopping Center. The World Managers argue that they are cultivating tastes and educating for progress...Telling poor people about products they have the money to buy right now, such as Coca Cola and ITT's Twinkies, opens up new horizons. How, the World Managers argue, can the transfer of the consumption ideology, which had so much to do with the expansion of the US economy, be bad for poor countries?

(Barnet and Muller 1974: 173)

The same helplessness of third-world peoples in the face of advertising by multinational corporations is cited by the critics of the powdered babyformula industry. A crucial ingredient to the success of these products is said to be the role of "opinion leaders," and again the impoverished are seen as emulating the elite.

But how all-powerful is advertising, and how constant is the emulation phenomenon? Mechanical models of innovation and diffusion, no matter how mathematically elegant, are usually post-hoc devices with equivocal explanatory power. They skirt the question of why people respond, or why they choose to remain unaffected.

Studies show that marketing and advertising are moderately successful in influencing brand choice, but are ineffective in creating primary demand for new product categories (Ray 1981; Zaltman and Wallendorf 1983). Advertising and diffusion effects may only augment, rather than create, existing trends. Furthermore, demand for foreign goods often grows in areas where there is no advertising, and consumers often request or pursue commodities which have not been pushed or marketed.

What are lacking in advertising models of consumer demand are concerns with internal processes, within societies and sub-groups. Treating indigenous cultures as black boxes and using "top down" models of demand can only take us part of the way towards the answers we seek. We will now turn to some perspectives on internal processes of demand. 
A considerable literature on the processes of innovation and spread of practices and artifacts takes up the question of which people are most likely to initiate demand and how demand spreads. Special attention has been given to the channels of communication both between the innovator and sources of information, and between innovators and followers (Rogers and Shoemaker 1971). Minimally, studies of innovation are descriptions of actual events and speculation about why innovators' practices are emulated and copied by others. Most studies are concerned with economically "rational" innovations which improve productivity (Rogers 1962). At best, however, the study of innovation involves an examination of the social context of innovation, and the kinds of competition between social strata which influence subsequent events (Cancian 1979).

The relationship between competition and consumption seems essential in clarifying the origins of demand as well, but in most innovation studies the focus on productive innovation clouds the issue. At their most basic, these studies are concerned with the processes of exchange of information and material culture, not with the genesis of a demand for innovation.

Classical economic theory has long used a simple and explicit model of demand which describes the basic consumer dilemma as choice between a series of alternative purchases. The goal is to construct indifference curves which depict how alternates are chosen, based on a posited mental ranking of values or "utility functions" (Haines 1973, Lerner 1969). By using the concept of "revealed preference," measuring the internal set of values by actual choice behavior, economists skirt the issue of how preferences originate and change (Houthakker 1950, Gorman 1971). These topics have never been of central concern since the pioneering studies of Veblen (Mason 1983).

In this, modern economists continue to follow the formulation of Alfred Marshall (1891), who claimed that economics was primarily concerned with production and exchange, and that demand (the Science of Wants) could be generally subsumed because wants were essentially infinite and could be taken for granted. His final words on the matter are quite prophetic:

Such a discussion of Demand as is possible at this stage of our work, must be confined to an elementary analysis of an almost purely formal kind. The higher study of Consumption must come after, and not before, the main body of economic analysis; and, though it may have its beginning within the proper domain of economics, it cannot find its conclusion there, but must extend far beyond. 
Economic anthropology has never explicitly taken up this task as its own. Production and exchange have dominated economic anthropology from its early years, but recent work on "primitive economics" has powerful and important implications for a theory of demand and consumption. One of the major conclusions to come out of the formalist-substantivist debate is that non-market economic systems limit and regulate access to and demand for most commodities by linking them to social positions and roles. Through exchange, but also through the accumulation and consumption of goods, social positions are enacted and transacted.

Perhaps the most basic example of limitation on consumption and accumulation through rules of social exchange is that of the band-level egalitarian society as discussed by Harris (1975). Because of rules of obligatory gift-giving, there is little incentive to produce or accumulate, and perhaps as important, to innovate. The establishment of reciprocal gift-giving bonds between two individuals or groups does provide some incentive for production and procurement of goods (Weissner 1982), but there are often strict social limitations on the kinds of goods which can circulate in such a manner. A Tiv expecting brass bars in exchange for a bride would be unlikely to accept a beach umbrella instead. In systems where politics and competition for power are predicated on the exchange and movement of particular classes of goods, the same limitations may apply.

In kinship-based socio-political systems, the consumption and accumulation of particular goods are the prerogative of particular kin roles. "In the world of the self-sustaining society, wealth has no existence apart from the individual, it is not dissociated from he who embodies the status of which it is the attribute" (Althabe 1962). The famous example of the stone axes among the Yir Yiront (Sharp 1952) illustrates the importance of the social control of particular categories of objects in the maintenance of social structure. A similar argument might be made for the circulation of bride wealth in West African societies. In both cases, the linkage between object and social position is so intimate that the introduction of new objects can create new roles and modify old ones, disrupting the distribution of power.

The exchange, extraction, and accumulation of goods within a particular social system rest ultimately on a shared system of values for the objects, a system which places some objects within the realm of "prestige" or "status" items. What Kwakiutl title-holders, Ashanti asafohene, and the emperor of ninth century Japan had in common was the control over the flow of these objects and a special right to their possession and use. What we have here is a proposed explanation for why people desire goods-as a means to acquire and transact their social positions. Within particular socially defined arenas, particular goods are sought, consumed, accumulated, destroyed, exchanged, and given away in particular situations for particular purposes. The assignment of meaning 
and value to objects is then a political and social process, in which the objects themselves are both the means and the ends.

Furthermore, the internal systems for the circulation of prestige goods are closely articulated with external systems of marketing and exchange. Jonathan Friedman has related the maintenance of marked political hierarchies and tribute in Eastern Polynesia to the maintenance of chiefly monopolies on long-distance exchange of prestige goods, and the smaller-scale, big-man systems of feasting distribution of goods in Melanesia to a higher density of inter-group exchange which allows no chiefly monopoly (1981; see also Rathje 1978). The contrast is between "societies... in which goods are accumulated and withdrawn from circulation for ceremonial purposes, often buried with great chiefs, and one in which all goods circulate in a more strictly 'economic' fashion" (Friedman 1981: 292). A similar linkage between political hierarchy and chiefly monopolies on long-distance exchange of prestige goods has been proposed for nineteenth century West African states (Coquery-Vidrovitch 1969, Rey 1973).

What is completely lacking, nonetheless, is a systematic depiction of how classes of prestige goods are defined or limited, and how and why they change over time, especially under the impact of western marketexchange systems. Friedman gives some interesting clues by noting that the more hierarchical Eastern Polynesian systems managed to feed imported western goods into existing prestige circulation, and thereby strengthen the power of the ruling group, while more open Western Polynesian systems disintegrated into civil war (see similar cases in West Africa discussed by Ekholm 1977). It would seem, however, that the competition for status using objects and goods is predicated on the system which defines objects and gives them their symbolic power. The symbolic attributes of objects are not themselves inherent, and are subject to negotiation, disagreement, and even conflict (F. Bailey 1969). This process is an essential part of the transfer of objects between cultural systems, when the very definition of the meanings and symbolic loadings of objects can change drastically.

Anthropologists who have explicitly studied symbolic systems and their dynamics have documented the ways in which symbolic objects and actions are related to each other as parts of larger ideological constructs. But the crucial matter for this discussion is how new objects are brought into existing symbolic systems, and how those systems change over time. They can explain to us why a white layer cake cut by a sword is consistent and complementary with the existing Japanese symbols of marriage, but they cannot explain why those symbols were sought, or how it happened that they were adopted in the first place (and why the cake can be made of plastic) (Edwards 1982).

When a sociopolitical system is changing, or when people are actively competing for power or status through the use of prestige goods, 
many objects will have ambiguous meanings which are the subject of dispute and negotiation. Sumptuary laws, which seek to punish those who improperly use objects, are a common result (although they are usually a futile stopgap, as in the Japanese case described by Shively [1955]).

Another crucial consequence (as some symbolic objects percolate downwards through the social scale or lose their power) is that those involved in competition may seek new objects from outside the existing systems-objects whose meaning and social role can be defined and controlled by themselves. A perfect example are the Czech enameled bowls, which secluded Hausa women in Ibadan have chosen to hoard in huge, carefully tended stacks, which are then used to attract unmarried errand girls and aides (Cohen 1969: 59, 66-68). Flannery (1968) has proposed that it is emerging elites, those who are struggling for legitimacy and an ideology which solidifies their power, who are most prone to systematically borrow both symbols and the content of those symbols from other elites who have successfully achieved a secure status. It is not a coincidence that the Japanese borrowed Chinese religion, philosophy, symbolic objects, and parts of the Chinese language at the very time that a ruling class was first transcending the previous kin-based political system and setting up a bureaucratic state (Wilk 1976). Islam was initially adopted into Sahelian political systems as part of a similar effort at solidifying a central authority (Trimingham 1964), and continues to expand as one response to European intervention.

The implication of these examples is that the circulation of objects of material culture between cultures cannot be separated from the processes by which objects circulate within cultures. The assignment of values and meanings to foreign objects is predicated on a system which regulates the assignment of meanings to all objects and actions within a cultural context. Moving towards general models of "boundary exchange" (see Cohen 1983) will therefore follow more directly if we are more specific in our discussion of the circulation and consumption of objects in general.

\section{Towards a taxonomy of modes of consumption}

The general absence of discussions of consumption in the anthropological literature stems partially from poor definition of the term and a tendency to meld aspects of consumption with social and material exchange and production. But the ties between individuals and groups created by shared consumption, and in the negotiation of the meaning of consumed objects are as real and important as those relationships stemming from production and exchange. To begin this discussion we will therefore define consumption in the broadest possible way, and then proceed to discuss some of the ways in which consumption might be divided and classified in a way which is useful in approaching the problems which have been outlined above. The discussion will rest upon, rather than 
repeat, the analytical and illustrative accomplishments of Hyde (1983) and Douglas and Isherwood (1979).

At the most general level, consumption consists of actions or activities which change the culturally assigned meanings and values of material objects. Consumption both changes the meaning of objects, and demonstrates them; it has connotations of "use." But in between active use of goods are passive periods of possession. Let us combine both acts of consumption and passive periods of possession into a process of consumption, which includes the entire period of time after a good is produced, until it is destroyed, exchanged, or disposed of. Certainly we must remove the comestible metaphor from the concept of consumption; consumption does not mean destruction, and often has the opposite effect. A Mercedes-Benz is often worth more after it has been consumed than before, and goods exchanged in Melanesia increase in value with each act of consumption.

Consumption begins when an object becomes an artifact, when it leaves the natural world and enters the cultural one through a process of production. Consumption only ends when an object leaves the realm of human society, when it departs from what Schiffer (1976) calls "systemic context" and enters the "archaeological context." Defining consumption in such general terms poses difficult problems in dealing with specific cases, and we have by no means worked out all the implications of defining consumption in this way. Nevertheless, this is a more useful definition than that offered by Douglas and Isherwood (1979: 57): "use of material possessions that is beyond commerce and free within the law." The emphasis here on freedom of choice in consumption is perhaps a byproduct of the desire to differentiate a category of "consumer goods" from other, presumably more utilitarian, goods which are subject to much less selection and choice. But, surely, this is a matter of degree rather than kind. From the Acheulean period of prehistory onwards, even the most utilitarian tools, like handaxes, have had a stylistic component which reflects consumer choice rather than strict utilitarian determination of function (see Jelinek 1976).

Further, should it not be said that food eaten without choice between alternatives (as with prison rations) is still "consumed"? Certainly the interplay between utilitarian function and "free choice" (what archaeologists call style) is a vital and important topic of investigation, but should our definition of consumption be predicated on such a complex investigation in each case?

Better to use a more general definition which allows many dimensions of contrast, and does not exclude whole categories of material culture. The definition we offer above allows many of the useful distinctions drawn by Douglas and Isherwood to be kept, defining kinds of consumption rather than cutting off consumption from other kinds of uses of artifacts. Thus consumption through production (as with a tool 
used up in the process of making other items) can be distinguished from consumption through display (for example, wearing jewelry).

Consumption by individuals can be differentiated from consumption by groups of people, and highly constrained consumption from that which is more unconstrained ("free").

\section{Consumption and exchange}

Exchange and consumption are intertwined, because the value and meaning of a good often change at the time of exchange. This leads us into making one of the most important distinctions within the general category of consumption, one which has been touched upon by all who deal with exchange and consumption. When consumption and exchange are so intertwined that the value and meaning of a good change as it moves from one owner to another, we are speaking specifically of gift exchange. On the other hand, when value and meaning are the same before and after the exchange, and no personal relationship has been created, a commodity exchange has taken place. It is possible to differentiate types of economies, depending on which kind of exchange is predominant, and to distinguish sub-types of both gift and commodity economies (see Gregory 1977). The differences have led some authors to posit a fundamentally different kind of "economic rationality" for giftexchange systems from that found in our own commodity-oriented society (see Mauss 1967, Sahlins 1972, Hyde 1983, Reilly and Arnould 1983).

Compared to commodity exchange, both the means and the ends of gift exchange appear to be distinctive. As Mauss pointed out in 1925, three norms as fundamental and unquestioned as our own concept of individual maximization behavior lie at the heart of gift exchange: the obligations to give, to receive, and to reciprocate. Goods are not predominantly acquired on the marketplace on the basis of agonistic relations amongst transactors through a rational decision amongst alternates, but are bestowed upon people in acts of apparent altruism.

The operation of these norms results in a constant flow of goods passing from hand to hand. As we know from studies of the Kula and the potlatch, among others, individuals were often only the temporary bearers and protectors of goods. When goods cannot be personally appropriated and consumed, they remain inalienable and enrich the patrimony of the whole group. In a sense, while individuals pass goods from hand to hand, the group as a whole actually consumes them.

By moving, gifts set up a perpetual reciprocal flow. Behind the concept of the "Indian Giver" bequeathed us by the Pilgrims, we can discern the Native American's urgent concern that the movement of goods be reciprocal. When the movement stops, the gifts become 
something else, the parties change from partners to strangers, and tend to continue the transformation, becoming enemies.

In consumer society a market transaction normally creates little effect on the social boundaries between buyer and seller. The immediate object is the consumption of the good. In contrast, in the gift economy each transaction makes, maintains, or redefines a social relationship. The focal point is not the goods, which are often standardized, but the transaction. In our society, "Coke is It," and the "it" is a happy communion provoked by Coke consumption, as graphically depicted in beach-party advertisements. In a gift economy the reverse occurs; Coke would be the recipient of special status by virtue of its role in the celebration.

The ends of gift exchange are not accumulation. Potlatchers might amass hundreds of blankets, Kula partners fathoms of shell necklaces, and New Guinea highlanders thousands of pigs, but the aim of such accumulation is dispersal in order create and accumulate social ties. Significantly, traditional concepts of wealth, such as the Hausa notion of arziki, gloss as disposition over persons, not goods. Gift debt creates personal obligation

In many societies which have only recently adopted commodity exchange, the memory of gift economies is still strong. Here the gift may come to represent an entire way of life which may or may not have ever existed. The gift is seen as an opposing principle to the commodity, and its strength and articulation may flow from cultural and political opposition to the inroads of commodities and the agents of the commodity economy. We should, therefore, be careful of reifying this opposition in our historical analysis; it is likely that all societies have elements of gift and commodity in their economies, and that the tension between the two provides both vitality and the potential for change and manipulation.

Rather than typologizing economies on the basis of their "exchange rationality," we might find more evocative and provocative questions in an exploration of the coexistence of the gift and the commodity. In practice, how do we differentiate, within the same cultural system, between exchange-without-consumption (the commodity) and exchangewith-consumption (the gift)? The distinction is admirably defined and dissected in Lewis Hyde's book (1983) The Gift: Imagination and the Erotic Life of Property .

In gift exchange the value of objects change, and the relationship between donor and recipient is transformed as a consequence. The function of the gift exchange is the changing of the relationship, and in the act the object exchanged is drastically affected.

To say that the gift is used up, consumed and eaten sometimes means that it is literally destroyed...but more simply and accurately it means that the gift perishes for the person who gives it away. In gift exchange, the transaction 
consumes the object. No, it is true that something often comes back when a gift is given, but if this were made an explicit condition of the exchange it wouldn't be a gift...This then is how I use "consume" to speak of a gift-a gift is consumed when it moves from one hand to another with no assurance of getting anything in return. There is little difference therefore between its consumption and its movement.

(Hyde 1983:9)

In a gift exchange, the motivating factor is the act of exchange: whatever the parties expect to achieve from consumption is largely accomplished in the act of transferring it. The life of a commodity, on the other hand, begins after the exchange; it is possession rather than exchange which is the intent of actors in respect to commodities. Hyde confuses the effects of gift-giving (the creation and maintenance of social ties, the breaking down of boundaries) with the definition of gifts as a general category. His mixing of the categories of exchange and consumption is useful in the case of the Kula and the Potlatch, but causes problems in more commonplace cases where exchange and consumption may overlap in complex ways, but may not be congruent.

It is possible to imagine an exchange in which the donor gains status and gratitude for giving an important and valuable object to a kinsman, who then claims that the object was given in payment for services rendered, and parades it around the village as a token of his prowess. Here the exchange is interpreted as a gift by some, and as a commodity exchange by others. The same object is consumed at the time of the exchange by the donor, and by the recipient through his possession and display. Our definitions must be flexible enough to allow us to discuss these important ambiguous cases, as well as the clear-cut extremes of the potlatch and the modern department store. In actual practice, most noncapitalist "gift" exchange systems actually oscillate between two modes of consumption, with periodic accumulation through commodity exchange and display, followed by massive gift-giving.

\section{Social limitations on consumption}

In many ways it can be argued that modes of exchange are predicated on modes of consumption. What motivates exchange of any kind, if not the desire to consume? It has commonly been observed in many pre-modern societies that goods cannot be exchanged freely for one another, but fall into categories of objects which can be exchanged for each other, or which must be acquired through gift exchange (Gregory 1982, Bohannon 1955, Davenport 1962). This peculiarity of exchange is in fact a function of the association of particular kinds of social roles and statuses with the consumption of particular kinds or class of goods. 
The human predilection for associating objects with social categories is an ancient one. The stronger the association, the more potential there is for people to change and alter their status through the manipulation of objects. Thus, the creation of strict rules creates the incentive for breaking them (this might be an addendum to Murphy's law). Much of social structure can be interpreted as systems meant to restrict material symbols to those who have earned or inherited them, to limit the consumption of goods. By consequence, social evolution and change, is largely the product of continual attempts to bypass or change those systems. ${ }^{2}$

The role of consumption in placing boundaries around groups of people, of creating and recreating those boundaries on a daily basis, is well known to archaeologists (e.g. Hodder 1981, Pollock 1983). But because consumption habits can change, can be mimicked or emulated, appearances may be deceiving. Archaeologists tend to assume that the material traces of consumption reflect social boundaries, when ethnographers show clearly that consumption can create and break down boundaries, and can be manipulated to cross them or dissolve them. Douglass and Isherwood emphasize the role of consumption in setting boundaries and "making visible and stable the categories of culture" (1979:59). But there is surely no need to make those categories visible unless they are also subject to question. The same devices which define social categories allow people to move across them. It is this fact which introduces an inherent, if culturally variable, dynamism into modes of consumption.

Thus to share in consuming items is to accept someone into the group, sometimes abruptly and sometimes gradually:

"Now that we have drunk, let us greet" is a frequently heard remark [in Northern Ghana], indicating that the verbal exchange of greetings and information should attend the act of hospitality, an act which turns the alien individual into a "stranger" to whom obligations attach, the principle of which is to provide him with food for a limited period. "After three days," runs a Sierra Leonan proverb, "you give him the hoe."

(Goody 1982:75)

Thus the alien becomes a guest, and then a producer and familiar member of the group.

Food is a particularly potent symbol of membership and boundaries, because it is consumed frequently by everyone-it can be extremely redundant as a source of information when there are few social distinctions to be drawn, but, at other times, it can be exquisitely sensitive

\footnotetext{
${ }^{2}$ Here we draw heavily on the work of Frederick Bailey and Abner Cohen among others.
} 
as a symbolic tool. In the United States, an invitation to a cold lunch, a buffet, a barbecue, or a cookout are devices to bring strangers to the threshold of intimacy, while attendance at cocktails and dinner takes them into the circle of more intimate friends (Farb and Armelagos 1980: 122). The definition of male and female foods or dishes is virtually universal, and is a frequent tool in the construction and maintenance of gender identities. As a popular manual of machismo has it, "Real Men Don't Eat Quiche."

Inclusion through shared consumption is the obverse of exclusion through prohibiting consumption. Secret knowledge and secret consumption are one solution to the problem of exclusivity, but the complementarity of inclusion and exclusion is revealed by the fact that the secret always lacks power and importance unless everyone knows that there is a secret that they are not allowed to have. We all recognize the pathology of possessing a stolen Picasso which can never be displayed, which nobody will ever know about. Similarly, Mbuti secret masks and ceremonies are known to all, but the illusion that they are male secrets is carefully maintained. "Secret Societies," like those of the Masons and the Rosicrucians, function through a series of nested secrets, so the recruit is always learning more, and is also learning that there are more secrets. ${ }^{3}$ The binding part of the secret is that it is consumed, possessed, by the initiate. Here again, the contrast between consumptionthrough-giving and consumption-through-possession is crucial. Perhaps secret sacred knowledge and artifacts were the first things which humans consumed-through-possession, and these "primitive commodities" then served as the avenue by which other kinds of possessions were developed. Initiation ceremonies sometimes involve... the revelation of hitherto secret knowledge; almost always they entail a change in diet and the relaxation of previous taboos (Farb and Armelagos 1980:99).

While societies of all kinds use the boundaries of secret knowledge and secret possessions to differentiate consumption and keep categories firm, those societies with complex and hierarchical institutions for leadership have developed other methods as well. The most common form these take are legal or quasi-legal restrictions on the consumption of particular categories of goods. The sumptuary laws of the Tokugawa regime of nineteenth century Japan have already been mentioned, and surprisingly similar sets of regulation are to be found in Medieval Spain (Defourneaux 1979) and France (Tuchman 1978), as well as in Aztec Mexico and almost any other early state which has been studied. The sacred rulers of even small chiefdoms were often distinguished by the consumption of special food, dress, ornamentation, drugs, and housing. In modern Niger, a precise social ranking can be based on different brands of cars. Only ministers may drive Peugeot 504s, for example.

\footnotetext{
${ }^{3}$ See Cohen (1981) for a discussion of how these societies function on a larger social scale.
} 
Anthropological accounts of chiefdoms tend to present a timeless snapshot of material culture, leading us to posit a perhaps illusory stability in the categories of what the elite were consuming. The view we get is that the elites in these societies were very successful in keeping the boundaries between elite consumables (the symbols and means of elite power) and "common" consumables relatively intact and stable. What the elite wanted to possess would have remained stable over long periods of time, and the consequence would be long-term stability in the styles of elite objects.

Certainly, what we see in historical data from state level societies is far from this posited stability. Sumptuary laws rarely work in the long run; despite often harsh punishments, people who "should not" be consuming particular items end up doing so, trying to change or even just retain their position within the system. Thus, elite symbols percolate downwards, losing their power in the process; this is what economists call the "snob effect" (Mason 1983). Burial in mound-tombs, originally the prerogative of the fourth century Japanese Emperor, had become so common by the sixth century that rich farmers were having mounds raised, and futile sumptuary regulations were enacted (Kidder 1959:160). The same process took place with Egyptian pyramids, the latest of which are no more than small piles of mud brick. The spreading consumption of Mercedes Benz, Rolls Royce, and Bentley automobiles among the aspiring elites of the American sunbelt seems to follow a similar logic.

It is probable that the rate of change in the styles of what the elite consumed were much slower in the less complex, gift-based economies of small chiefdoms, than they were in complex states and modern commodity-based economies. Since archaeologists have tended to measure the passage of time by looking at stylistic change in artifacts, they are hampered in comparative studies of the rates of change under different social circumstances. It is certainly clear that, even in the relatively simple chiefdoms of the American prehistoric Pueblo Southwest or the Pre-classic Maya of Mesoamerica, some categories of material culture (for example scrapers and ground stone milling stones) changed very slowly, while others (notably decorated ceramics) changed shape and decoration very quickly. Questions of degree of competition through consumption in different kinds of societies must therefore await more careful empirical analysis. We should not just assume that chiefdoms are static and ridden with stable consumption patterns, while states are more dynamic and changeable.

If there are pressures in every society for the widening of consumption groups, the breaking down of barriers to consumption and the sharing of the power conferred by exclusive rites to consumption, how then is stability ever achieved? It is not possible here to summarize all the ways in which boundaries are made concrete and reinforced against transgression, but we should mention a few of the more 
important ones. The Aztecs always held out the prospect of achieving more rights to consumption through accomplishment on the battlefield: capture one prisoner and have the right to wear white clothes; capture two and get a headdress.

Controlling access to the actual physical material for consumption through force or ownership is a very important method. Elites, from earliest times, control-or attempt to control-the exchange of foreign goods. By control we mean limit access to them, not facilitate cheap and ready movement. This explains why people like the Olmecs and Sumerians were so intent on taking exotic consumer goods like jade and gold out of circulation by burying them. Reciprocal ties between elites are crucial to maintaining the monopoly on exchange of such items (see the discussion by Cohen [1983] of how elites can actually emerge through the control of such trade). As long as an exchange system remains closed, and inter-regional trade lies in the hands of the elite, consumption of restricted classes of goods can be limited, and the limitations can remain stable. The principle of elite monopoly, still seen in goods like diamonds, is certainly an ancient one. An alternate strategy, followed by elites in many African kingdoms (as well as by the Uji clans of Yamato period Japan), was to attach craft producing groups to the elite households or courts. The elites enjoyed privileged access to the goods produced, encouraging the preservation of trade secrets, and sharing in the fruits of exchange and trade in them (e.g. Nadel 1942).

Theorists have posited that the earliest societies to develop strong political hierarchies were then able to stimulate the formation of elites in other societies through the extension of the monopoly on elite goods: external trade brings exotic prestige artifacts, which confer status on those individuals controlling the supply. A prominent hierarchy can thus emerge in what was formerly only a partially stratified society. In this case, the society supplying the goods is already highly organized and stratified, and with the goods comes information, a set of values, and social procedures which are more readily adopted because of the sophistication of the source society's products and the prestige in which they are held. (Renfrew 1975:33, see also Flannery 1968)]

The trade of such objects is not enough; they must be integrated into each society's symbolic system in such a way that their consumption is meaningful, and does strengthen rulership in desired ways. Those involved in such trade are often aware of the necessity for display, as well as trade. When the powerful Emperor of China received "gifts" of slaves from a Japanese chieftain in the early third century A.D., he sent gifts in return, along with the following revealing message:

We have granted them (the ambassadors from Japan) audience in appreciation of their visit, before sending them home with gifts. The gifts are these: five pieces of crimson brocade with dragon designs; ten pieces of crimson tapestry 
with dappled pattern; fifty lengths of bluish-red fabric and fifty lengths of dark blue fabric. These are in return for what you sent as tribute. As a special gift we bestow upon you three pieces of blue brocade with interwoven characters, five pieces of tapestry with delicate floral designs, fifty lengths of white silk, eight taels of gold, two swords, five feet long, one hundred bronze mirrors, and fifty catties each of jade and red beads...When they arrive and you acknowledge their receipt, you may exhibit them to your countrymen in order to demonstrate that our country thinks so much of you as to bestow such exquisite gifts upon you.

(Tsunoda1951: 14-15)

The cloth was an ideal consumer good, which was turned into clothes and decorations for the ruler and his court. The mirrors and swords were used in Japan as sacred objects, representing the power of the leader in the Shinto cult. The beads were buried with the elite at death.

Another means of limiting consumption of goods to particular groups or individuals is through the involvement of the dead in consumption. Goods are not always consumed at the death of the consumer. Instead, they can be transferred from generation to generation; when their value is based on a series of generational transmissions, they become a powerful exclusionary device, and an excellent means of limiting the flow of symbols downwards in social level. Old wealth is qualitatively different from new wealth-this tradition survives even in our own society. Consumption can symbolize continuity, and it is no coincidence that elites are so concerned with rites of the dead, and have designed especially elaborate consumption-rituals to accompany the burial of high status dead.

Through inheritance of goods for consumption, or through their transmission via brideprice or dowry, the consumption of goods is inextricably linked with social ties between kin. Again, consumption of goods is restricted by limiting the terms of exchange for them. In some societies, like those of the Tiv and Lele in Africa, spheres of exchange involving women and consumption goods (certainly people can be "consumed," as we have defined the term) are preeminent. It is to be expected that consumption of this kind, delimited and limited by negotiable and non-negotiable bonds of kinship, has special dynamics of its own, and may prove to provide boundaries which are most resistant to change. Kinship structures persist in commodity-exchange based societies like our own, at least partially because they continue to be spheres in which gift exchange is important (Hyde 1983: 95-102). Goods which are consumed within the bounds of the family are still subject to very special rules; strangers are not allowed to partake of the exchanges between husband and wife. 


\section{The definition of meaning in consumption}

As we have mentioned above, the consumption of goods is a crucial activity in both creating and changing systems of meaning, and the categories of culture. Above we have discussed some of the ways that the meanings of goods are stabilized or disputed; here we will define some terms which help move the discussion of consumption forward. ${ }^{4}$

The most general terms we will use are symmetry and asymmetry. In a symmetrical situation, all members of a society agree on the meaning of goods, both those who consume them and those who do not. In a system of asymmetry, however, there is disagreement over the meaning of goods: because they are new, because some people are trying to change the meaning of those goods, or for other reasons (which merit further research). Here we are speaking of public meanings only, ignoring for the moment the "bivocal" (Cohen 1981) character of symbols, that they have individual and personal meanings, as well as impersonal and public ones. The contest over asymmetrical meanings is a counterpoint to the agreement over symmetrical meanings; we can also apply these terms to the partners in an exchange.

In order for symmetry to be maintained in a changing social scene, or for asymmetry to be resolved, the meanings of goods must change, must go through transformations. The transformation of the meanings of goods is one of the central concerns of actors in any society, and we can broadly define several kinds of transformation process.

Competition is the general term we will use for contest and dispute over the meaning of goods and over their uses. Unless the system tolerates ambiguity (often through the use of secrecy), allowing asymmetry of meaning to persist without dispute, competition of some kind will take place. This competition is managed in a number of ways:

Displacement eliminates a category of goods and replaces it with a new one which has the same meaning. This can be envisioned as an old category being transformed into a new one through substitution. Hudson's Bay blankets in the Northwest coast might be an example.

Identification involves the linking of categories of meaning together, so that a new object takes on aspects of an old one. Airtight efficient woodstoves are accepted because they are given meanings associated with open fireplaces and cooking hearths.

Promotion is the lifting of an item by a series of steps in a graded hierarchy of meanings within a larger category. Thus, running shoes are promoted from the level of athletic footwear to the level of fashion footwear.

\footnotetext{
${ }^{4}$ This discussion draws heavily on the work of F. Bailey and Y. Cohen.
} 
Appropriation removes a good from competition by linking its consumption to a particular situation or category of person. Until quite recently bright hair coloring in our society was not subject to competition; the practice had been appropriated by older women, especially widows.

Escalation sees the widening of a dispute over the meaning of particular goods to include other matters. This may take the form of identification, as the meaning of new objects is linked to the meaning of old ones. When modern towns decide who may or may not consume video games, alcohol, or pornographic literature, they generally compete by escalating the dispute to include other matters, such as the morality of divorce, the education of children, the amount of crime, and so on. In extreme cases, a combination of escalation and identification can spread a dispute over the meaning of objects so widely that chaos ensues and the very fabric of society is threatened. This seems to be what happened to the Yir Yiront in the case of the steel axes. This case should be contrasted with that of the introduction of shotguns into New Guinea, where appropriation took place and the stability of the system was maintained (Mitchell 1973).

\section{Change in consumption}

Given these admittedly incomplete definitions of process, we are now in a position to talk about change in consumption in a systematic way by envisaging a cycle by which new objects and meanings are brought into circulation, showing how symmetry and asymmetry alternate in a cyclic pattern. In this model, the manipulation of symbolic objects in public and private contexts ordinarily exploits their ambiguity. Innovation occurs when this manipulation actually transgresses the boundary of acceptable manipulation, As Bailey (1969) points out, this creates contradictions in the system of meanings embodied by the symbol; there is now asymmetry of meaning between the members of the group which must be resolved. All of the means mentioned above can be used in this resolution, and the results are either a return to the status quo, a change in the system of meanings, or some degree of chaos. In the two former cases, symmetry is reestablished. Change in consumption regime is a kind of social drama (Turner 1974).

The most provocative question to arise from use of this model concerns motivation, which impels the use of objects or symbols in ways which cause asymmetry. Who are the innovators, the entrepreneurs (Barth 1963), the outcasts, upstarts, angry young men, avant garde, tastemakers, rebels, deviants, and manipulators? Why choose symbolic competition, breaking the bounds of convention, rather than some other form of competition? One is reminded of the example of the Aztec Pochteca, the medieval European Jewish moneylenders, and the nineteenth century Japanese merchant classes-groups which amassed 
wealth, but did their best to disguise it, to give the appearance of poverty, taking pains to stay within the social persona assigned them, even though economic changes had given them the capability of consuming at a much higher level. In the Japanese case, at least, there has always been a careful distinction drawn between real power, and the display of power; they have a long tradition of "powers behind the throne," who appear to be ordinary people, while those who consume and display all the trappings of power are in fact powerless.

Lewis Hyde argues that the single, and perhaps fatal, flaw in systems of gift exchange is the damping of individual expression, which flows from participation in the greater commonality. He says that there are therefore always times when we wish to act upon our disconnection from the group, times when bonds become strictures. The "excitement of commodities" for those living in a gift-based economy may lie in the possibility of alienation. Young people, who are often prohibited from full participation in the consumption of gifts, are the first to be lured away. Hyde says that "all youth wants to be alienated from the bonds that nurture, to be the prodigal son. Sometimes we go to the market to taste estrangement" (1983:67-68).

In the New Guinean societies discussed by Gregory (1983), and in many Sahelian societies (Meillassoux 1981), youth also goes to the market with the intention of obtaining familiar consumption goods using new methods. Their intent may be to participate more fully in their own community's patterns of consumption, but they usually end up returning with competing goods. New symbols and new knowledge which they bring home inevitably introduce "asymmetry" into existing systems of meaning. Thus, the Lele system of ranking survived only through the successful exclusion of Belgian Francs from the system of meaningful commodities, while the Tiv system burst apart under the pressure of British coinage when that medium was accepted as meaningful (Douglas and Isherwood 1979).

As Mintz (1979) points out, there is a feedback relationship operating here between demand and supply-one which economists count on, but do not really understand. A key to understanding it may be found in Goody's discussion of changing consumption patterns among elites in West Africa (1982). He begins with an historical discussion of social structure, emphasizing that predominant social divisions were permeable and vertical, between lineages, clans, moieties and tribes. While commodity production and exchange were common, they did not form the basis for horizontal class divisions.

Material culture tended to be more uniform, less differentiated by social rank, than in Eurasian societies. The elite consumed more of everything, but not different kinds of things, and this was directly reflected in the elite cuisine (Goody 1982:204-205). The colonial experience can be seen as a transformation from consumption 
differentiated by quantity into consumption which differentiates by quality as well.

Consumption patterns changed in concert with productive systems. Colonialism disrupted consumption units by encouraging individualized production of cash crops, migrant wage labor, and task specialization. Thus, production also came to be differentiated by quality (measured by labor value) where before it had been mainly measured by quantity.

As new productive arrangements emerged, new demands emerged, and colonizers introduced novel industrial foods. Some helped to overcome seasonal cycles of glut and famine through superior storability (as with tinned beef and fish). Bread, that compact and transportable food of conquerors, also arrived and was absorbed. Drugs and cheap energy foods met the demands of new classes of labor. As they had in Europe, tobacco, beer, coffee, sugar and tea changed from luxuries into staples.

What of the new bureaucratic, military, and entrepreneurial elites who rose under the tutelage of the colonial powers? Their social position is highly ambiguous, lacking traditional legitimacy, as well as traditional duties and obligations. They are neither gift givers nor gift receivers. Their relationship with colonial powers-far from being one of emulating the admired-is equally ambiguous.

Goody (1982) suggests that their solution has been to borrow the "gear of western modes of consumption," to fill in where they lack models for differentiated cuisine, couture, and architecture within their own cultures. The attachment to traditional modes of consumption is still strong in a reduced sphere of domestic gift exchange, but formal occasions require formal food, drink and clothing. These tend to be defined as Eurasian, and are acquired through impersonal market transactions. Both Moslem and European cultures provide the models; hence one sees the juxtaposition of leopard skins and movie cameras at a ceremony at once formal and domestic-that is, at the marriage mentioned at the beginning of this essay.

Emerging elites borrow both symbols and the content of symbols from other cultures. They emulate elites who have secure and stable social status. Competing groups may even choose to emulate different foreign elites; one group may choose Pumas, the other Adidas; one Guinness, and the other Schlitz.

\section{Conclusions}

Explaining how culture contact leads to the diffusion of goods is ultimately just a part of a social science of demand. Anthropologists must take the lead in this endeavor. The economist's marginal utility theory, as well as the Marxist and humanist alternatives, agree that consumption patterns are inherently dynamic within an economy dominated by 
commodity exchanges. But no discipline or dogma offers a theory for explaining what goods will be adopted, nor why, nor how. Until we possess more studies (and more sensitive studies) of adoption which deal with the social basis of consumption, answers will tend to be based more on dogma than fact.

In addition to the suggestions offered above, there are other clues about where and how to look at the diffusion of new goods to new consumers. One important domain of inquiry is that which economists call "exceptional consumer behavior," or "non-functional demand" (Mason 1983). Examples are the bandwagon, Veblen, and auto-ritual effects (see Rook and Levy 1982 also). Bandwagon effects occur when demand snowballs, and the main reason for acquiring a good is that others have already acquired it. Veblen, or snob, effects are those where demand increases as price rises, rather than vice versa. An auto-ritual effect is demand which crystalizes around private atavistic fantasies.

All of these effects violate the core assumptions of formal economic marginal utility theory, rather than just secondary assumptions such as perfect information and profit maximization (which have already been relaxed in marketing theory). They show that satisfaction is not a function of utility, but of real or imaginary audience involvement. Maximization is not achieved in the isolation of the consumer's home as a private individual outcome, but in a social setting with the participation, and even at the expense, of other consumers.

This kind of behavior inevitably involves the "irrational," or erotic, rather than the "rational," component of goods. The imagination and affective lives of consumers are drawn to the market with a combination of counterfeit gifts ("free" samples, introductory offers, million-dollar sweepstakes, and exclusive tastings) and advertising images which draw on the deepest emotional bonds. The liveliness of the imagination is enlisted to move products quickly, before the fad passes, the exotic becomes mundane, or the exclusive becomes the norm. These unexplored territories of consumer behavior are as rich a source of information on modes of consumption as the gift giving of any aboriginal festival. While the answer to the question of why natives wear Adidas does not require us to know why New Yorkers wanted them first, both questions relate to the more essential issues of the social nature of material culture.

The apparently comical images cited in the first paragraphs of this paper are important ones: they are generated by powerful social imperatives embedded in modes of consumption. Our ignorance of the dynamics of these patterns is appalling, considering the importance of consumption in the modern world system. Around the world, each system has developed means of regulating the flow of goods and the assignment of meanings to them. Systems differ in the degree to which goods may be manipulated and access to them can be restricted, in the points of entry for new objects, in the occasions for the display and use of new objects, 
and in their rules for transfer of objects from person to person and group to group.

\section{References}

Althabe, G. 1962 Problèmes socio-économiques du Nord-Congo. Cahiers de l'ISEA 5 (5).

Bailey, F. G. 1969 Stratagems and Spoils. New York: Schocken.

Barnet, Richard and Ronald Muller 1974 Global Reach. New York: Simon and Schuster.

Barth, Frederik (ed.) 1963 The Role of the Entrepreneur in Social Change in Northern Norway. Oslo: Scandinavian University Books.

Belk, Russell 1982 Worldly Possessions: Issues and Criticisms. Paper Presented at the Association for Consumer Research Annual Conference, San Francisco.

Bohannon, Paul 1955 Some Principles of Exchange and Investment among the Tiv. American Anthropologist 57: 60-70.

Burnham, John C. 1968 Historical Background for the Study of Personality. In Edgar Borgatta and William Lambert (eds.), Handbook of Personality Theory and Research. Chicago: Rand McNally and Co., pp. 3-81. Cancian, Frank 1979 The Innovator's Situation. Stanford: Stanford University Press.

Cocanougher, A. B. and G. D. Bruce 1972 Socially Distant Reference Groups and Consumer Aspirations. Journal of Marketing 36: 12-19.

Codere, Helen 1950 Fighting with Property. New York: Augustin.

Cohen, Abner 1969 Customs and Politics in Urban Africa: A Study of Hausa Migrants in Yoruba Towns. Berkeley: University of California Press.

Cohen, Abner 1981 The Politics of Elite Culture. Berkeley: University of California Press.

Cohen, Yehudi 1983 A Theory and a Model of Social Change and Evolution. Journal of Anthropological Archaeology 2 (2): 164-207.

Coquery-Vidrovitch, C. 1969 Recherches sur un mode de production africain. La Pensée 144 (April): 61-78.

Davenport, W. 1962 Red Feather Money. Scientific American 206 (3): 94105.

Deforneaux, Marcelin 1979 Daily Life in Spain in the Golden Age. Stanford: Stanford University Press.

Douglas, Mary and Baron Isherwood 1979 The World of Goods. New York: Basic Books. 
Drucker, Philip 1965 Cultures of the North Pacific. Scranton: Chandler Publishing Co.

Ekholm, K. 1977 External Exchange and the Transformation of Central African Social Systems. In J. Friedman and M. Rowlands (eds.), The Evolution of Social Systems. London: Duckworth.

Ewen, Stewart 1976 Captains of Consciousness: Advertising and the Roots of Consumer Culture. New York: McGraw Hill.

Farb, Peter and George Armelagos 1980 Consuming Passions: The Anthropology of Eating. New York: Washington Square Press.

Fitchen, Janet M. 1981 Poverty in Rural America: A Case Study. Boulder: Westview Press.

Flannery, Kent V. 1968 The Olmec and The Valley of Oaxaca: A Model for Inter-Regional Interaction in Formative Times. In Elizabeth Benson (ed.), Dumbarton Oaks Conference on the Olmec. Washington D.C. : Dumbarton Oaks, pp. 79-117.

Friedman, Jonathan 1981 Notes on Structure and History in Oceania. Folk 23: 275-295.

Furtado, Celso 1963 The Economic Growth of Brazil. Berkeley: University of California Press.

Godelier, Maurice 1977 Perspectives in Marxist Anthropology. Cambridge: Cambridge University Press.

Tsunoda, Ryusaku(translator1951 Japan in the Chinese Dynastic Histories. Perkins Asiatic Monographs 2. South Pasadena: P.D. and I. Perkins.

Goody, Jack1977 The Domestication of the Savage Mind. Cambridge: Cambridge University Press.

Goody, Jack 1982 Cooking, Cuisine and Class: A Study in Comparative Sociology. Cambridge: Cambridge University Press.

Gorman, W. M. 1971 Preference, Revealed Preference, and Indifference. In C. Chipman (ed.), Preferences, Utility, and Demand. New York: H.B.J., pp. 81-114.

Gregory, C.A. 1982 Gifts and Commodities. London: Academic Press.

Gross, Daniel, G. Eiten, N. Flowers, F. Leoi, M. Ritter, and D. Werner 1979 Ecology and Acculturation among Native Peoples of Central Brazil. Science 206: 1043-1050.

Haines, G. 1973 Overview of Economic Models of Human Behavior. In S. Ward and T. S. Robertson (eds.), Consumer Behavior: Theoretical Sources. New Jersey: Prentice Hall, pp. 276-300.

Harris, Marvin 1975 Culture, People, and Nature: An Introduction to General Anthropology. New York: Thomas Crowell. 
Hodder, Ian 1981 Symbols in Action. Cambridge: Cambridge University Press.

Houthakker, H. S. 1950 Revealed Preference and the Utility Function. Economica 17: 33-45.

Hyde, Lewis 1983 The Gift: Imagination and the Erotic Life of Property. New York: Vintage Books.

Isichei, Elizabeth 1973 The Ibo People and the Europeans. New York: St. Martins.

Jelinek, Arthur 1976 Form, Function, and Style in Lithic Analysis. In Cultural Change and Continuity: Essays in Honor of James Bennett Griffin. New York: Academic Press, pp. 19-33.

Katona-Apte, Judit 1975 Dietary Aspects of Acculturation: Meals, Feasts, and Fasts in a Minority Community in South Asia. In Margaret Arnott (ed.), Gastronomy: The Anthropology of Food and Food Habits. The Hague: Mouton, pp. 315-326.

Kidder, J. E. 1959 Japan bfore Buddhism. London: Thames and Hudson.

Lerner, A. 1969 The Analysis of Demand. In S. Blumner (ed.), Readings in Microeconomics. Scranton: International Educational Publishing Company, pp. 46-62.

Linnekin, Jocelyn S. 1983 Defining Tradition: Variations on the Hawaiian Identity. American Ethnologist 10 (2): 241-252

Marshall, Alfred 1891 Principles of Economics. (2nd ed.) London: Macmillan and Co.

Marx, Karl and Friederich Engels 1955/1848 The Communist Manifesto. Samuel Beer, editor. New York: Appleton-Century-Crofts.

Mason, R. S. 1983 The Economic Theory of Conspicuous Consumption. International Journal of Social Economics 10 (3): 3-17.

Mauss, Marcel 1967 The Gift: Forms and Functions of Exchange in Archaic Societies. New York: Norton.

Mead, Margaret (ed.) 1955 Cultural Patterns and Technical Change. New York: UNESCO.

Meillassoux, Claude 1981 Maidens, Meal and Money. Cambridge:

Cambridge University Press.

Mintz, Sidney 1979 Time, Sugar and Sweetness. Marxist Perspectives 2: 56-73.

Mitchell, William E. 1973 New Weapons Stir Up Old Ghosts. Natural History 82 (6): 75-84.

Murphy, Robert and Julian Steward 1956 Tappers and Trappers: Parallel Process in Acculturation. Economic Development and Social Change 4: 335-353. 
Nadel, S.F. 1942 A Black Byzantium: The Kingdom of the Nupe in Nigeria. London: Oxford University Press.

Pollock, Susan 1983 Style and Information: An Analysis of Susiana Ceramics. Journal of Anthropological Archaeology 2 (4): 354-390.

Rappoport, Roy 1968 Pigs for the Ancestors. New Haven: Yale University Press.

Rathje, William 1978 Melanesian and Australian Exchange Systems: A View from Mesoamerica. In J. Specht and P. White (eds.), Trade and Exchange in Oceania and Australia. Sydney: Australian Museum, pp. 165174.

Ray, Michael L. 1981 Advertising and Communications Management. Upper Saddle River, NJ:Prentice Hall College Division.

Reilly, Michael 0. and Eric J. Arnould 1983 Exchange, Culture and Rationality: On the Limits of the Exchange Paradigm. Department of Marketing Working Paper. Arizona: Tucson.

Renfrew, Colin 1975 Trade as Action at a Distance. In J. Sabloff and C. C. Lamberg-Karlovsky (eds.), Ancient Civilizations and Trade. Albuquerque: University of New Mexico Press, pp. 3-60.

Rey, Pierre-Philippe 1973 Les alliances de classes. Paris: Maspero.

Rogers, Everett M. and F. Floyd Shoemaker 1971 Communication of Innovations: A Cross-Cultural Approach. New York: Free Press.

Rogers, Everett M. 1962 Diffusion of Innovations. New York: Free Press.

Sahlins, Marshall 1972 Stone Age Economics. Chicago: Aldine.

Salisbury, Richard 1962 From Stone to Steel. Cambridge: Cambridge University Press.

Schiffer, Michael B. 1976 Behavioral Archaeology. New York: Academic Press.

Sharp, Lauriston 1952 Steel Axes for Stone Age Australians. In Edward Spicer (ed.), Human Problems in Technological Change: A Casebook. New York: Russell Sage.

Shively, Donald 1955 Bakufu Versus Kabuki. Harvard Journal of Asiatic Studies. 18 (3-4): 326-356.

Spicer, Edward H. (ed.) 1951 Human Problems in Technological Change. New York: Russell Sage.

Stout, D. B. 1947 San Blas Cuna Acculturation: An Introduction. Viking Fund Publications in Anthropology 9. New York: Columbia University.

Strathern, A. J. 1969 Finance and Production: Two Strategies in New Guinea Highland Exchange Systems. Oceania 90 (1): 42-67. 
Strathern, A. J. 1971 The Rope of Moka. Cambridge: Cambridge University Press.

Trimingham, John S. 1964 A History of Islam in West Africa. London: Oxford University Press.

Tuchman, Barbara 1978 A Distant Mirror: The Calamitous 14th Century. New York: Ballantine Books.

Turner, Victor 1974 Dramas, Fields, and Metaphors: Symbolic Action in Human Society. Ithaca: Cornell University Press.

Vayda, Andrew P. 1961 A Re-examination of Northwest Coast Economic Systems. Transactions of the New York Academy of Sciences Series 2, 23: 618-624.

Vayda, Andrew P. 1967 Pomo Trade Feasts. In G. Dalton (ed.), Tribal and Peasant Economies. Gardner, NY: Natural History Press, pp. 494-500.

Veblen, Thorstein 1899 The Theory of the Leisure Class. New York: Macmillan.

Wallerstein, Immanuel 1974 The Modern World System. New York: Academic Press.

Weissner, Polly 1982 Risk, Reciprocity and Social Influences on !Kung San Economics. In Eleanor Leacock and Richard Lee (eds.), Politics and History in Band Societies. Cambridge: Cambridge University Press, pp. 61-84

Wilk, Richard R. 1976 Is Pristinity Necessary? An Investigation into Chinese Influence on the Evolution of Early Japanese Political Systems. Paper on file with the Arizona State Museum, Tucson, Arizona.

Wilks, Ivor 1979 The Golden Stool and the Elephant Tail: An Essay on Wealth in Asante. Research in Economic Anthropology 2: 1-36.

Wilson, Edward O. 1975 Sociobiology. Cambridge, MA: Harvard University Press.

Zaltman, Gerald and Melanie Wallendorf 1983 Consumer Behavior: Basic Findings and Management Implications. New York: John Wiley \& Sons. 